\title{
ALFREDO GALLIS, O PORNÓGRAFO ESQUECIDO
}

\author{
ALFREDO GALLIS, THE FORGOTTEN PORNOGRAPHER
}

Aline Moreira DUARTE (UERJ)

\begin{abstract}
Resumo: No Brasil do final do século XIX, a partir de 1880, ocorre um crescimento expressivo do interesse do público e dos livreiros por obras licenciosas. Para atender a essa demanda, muitos escritores aderiram à moda, produzindo narrativas que, sob a voga cientificista do naturalismo, colocavam o corpo e o desejo sexual em questão a fim de desmascarar as hipocrisias da sociedade burguesa. O escritor naturalista português Joaquim Alfredo Gallis (1859-1910) foi esquecido pela historiografia literária justamente por ter se "manchado" com a literatura pornográfica. Nesse estudo, além de apresentar o ilustre, porém esquecido, Alfredo Gallis, pretendemos produzir um conhecimento novo a respeito da literatura licenciosa do final do século XIX, tomando como objeto de estudo um dos autores pornográficos mais conhecidos do período.
\end{abstract}

Palavras-chave: Século XIX. Literatura pornográfica. Alfredo Gallis.

\begin{abstract}
At the end of the nineteenth century in Brazil, starting in 1880, there was a significant increase in the interest of the public and booksellers for licentious works. To meet this demand, many writers started to create narratives that, under the scientific vogue of naturalism, put the body and sexual desire in question in order to expose the hypocrisies of bourgeois society. The naturalist Portuguese writer Joaquim Alfredo Gallis (1859-1910) was forgotten by literary historiography precisely for having been "stained" with pornographic literature. In this study, besides introducing the illustrious, but forgotten, Alfredo Gallis, we intend to produce a new knowledge about the licentious literature of the late nineteenth century, taking as object of study one of the best known pornographic authors of the period.
\end{abstract}

Keywords: Nineteenth century. Pornographic literature. Alfredo Gallis.

\section{Introdução}

A historiografia literária costuma ser determinada pela seguinte dinâmica: existem as obras de autores "dominantes", donos de "capital simbólico" incontestável e que ocupam uma categoria superior em relação a outro grupo de escritores, os "dominados", que por variadas razões não alcançaram o reconhecimento necessário para se legitimarem histórica e literariamente (BOURDIEU, 1996). A historiografia costuma se limitar a apresentar as obras dos autores dominantes, as quais destaca por meio da "qualidade estética" ou "valor literário", mas omite as batalhas - muitas vezes impiedosas - pela dominância no campo artístico, assim como a genealogia dos critérios definidores de qualidade e valor. Por razões nem sempre claras ou justas, opera-se a exclusão de incontáveis autores. 
Este é o caso do escritor português Joaquim Alfredo Gallis (1859-1910), ainda pouco conhecido na área dos Estudos Literários. Diante de uma fortuna crítica ainda limitada, é através da leitura de fontes primárias - revistas e periódicos da época, hoje disponibilizados online que encontramos informações a respeito da vida e da obra do autor, através de anúncios de publicações à venda, registros de leitura, inventários de acervos de bibliotecas, comentários, resenhas, entre outros. Além disso, contamos com os seguintes trabalhos recentes: o estudo de Maria Helena Santana, "Pornografia no fim do século: os romances de Alfredo Gallis" (2004); o posfácio de uma nova edição portuguesa dos contos licenciosos do autor, por Antonio Ventura, "Rabelais, isto é, Alfredo Gallis, o pornógrafo" (2011); o estudo sobre os best-sellers pornográficos no Brasil no final do século XIX, de Leonardo Mendes, "Livros para homens: sucessos pornográficos no Brasil no final do século XIX” (2016); e o livro Páginas de sensação: literatura popular e pornográfica no Rio de Janeiro (1870-1924) (2004), da pesquisadora Alessandra El Far.

Como muitos escritores de sua época, Alfredo Gallis aderiu à moda da literatura licenciosa e foi um dos pornógrafos de maior sucesso no circuito luso-brasileiro no período. No final do Oitocentos, os ideais de progresso e modernização causaram impactos não só no âmbito tecnológico, como também cultural. No Brasil, a partir de 1880, uma marca dessa modernização foi a visibilidade crescente dos livros pornográficos, especialmente no Rio de Janeiro, um fenômeno que estava relacionado ao processo de popularização do livro no período (EL FAR, 2004). Na medida em que a literatura deixava de ser privilégio da elite letrada, surgia um mercado livreiro interessado em atrair público mais diversificado. Entre os livros populares, aqueles que se voltavam para a temática sexual eram os que mais chamavam a atenção do novo público leitor.

Numa sociedade conservadora como aquela, é curioso que esses livros tenham atingido uma popularidade tão expressiva. Os livros pornográficos atraíam não só pelo baixo custo entre 2 e 3 mil-réis, equivalente a uma refeição digna no Largo da Carioca -, mas também por convidarem o leitor ao universo privado das alcovas em que o prazer sexual era um fim em si mesmo, desvinculado do imperativo religioso da procriação. Nesse sentido, apesar da grande popularidade, esses livros ofereciam perigo ao padrão burguês de contenção dos impulsos. No caso de Alfredo Gallis, os críticos e intelectuais da época eram unânimes: apesar do grande talento, o caráter licencioso de suas obras, dotadas de "um excesso de 'crueza' naturalista, devéras lastimavel", ${ }^{1}$ causou uma mancha em sua carreira (VENTURA, 2011). Nesse estudo,

1 Correio Paulistano, São Paulo, n. 17.022, 21 dez. 1910, p. 6.

Revista Graphos, vol. 19, n², 2017 | UFPB/PPGL | ISSN 1516-1536 
além de apresentar esse autor esquecido, pretendemos discorrer sobre as pressões sociais que regem o campo intelectual (BOURDIEU, 1996) e afetam a historiografia literária, tomando como objeto de estudo a obra pornográfica de Alfredo Gallis, escritor cuja fama foi vencida pelo rígido convencionalismo social que condenava as representações do corpo e do sexo.

\section{O pornógrafo esquecido}

No espaço virtual do "Projecto Vinculados ao Barreiro", ${ }^{2}$ vemos que Joaquim Alfredo Gallis nasceu em Lisboa, no ano de 1859 - em que dia exatamente não sabemos -, e morreu em 24 de novembro de 1910. O texto demonstra que, em Portugal, o escritor era conhecido basicamente por seu trabalho como jornalista e servidor público. Começou sua carreira jornalística no jornal Instituições, em 1879; colaborou nos jornais Universal, Jornal do Comércio, Liberal, Ecos da Avenida e Diário Popular; foi administrador do concelho do Barreiro de 1901 a 1905; exerceu o cargo de escrivão da corporação dos Pilotos da Barra de Lisboa, onde conheceu o rei D. Carlos, com quem mantinha boas relações; e foi também secretário do governador civil de Lisboa até o ano de sua morte.

Sobre sua atuação como escritor, o leitor é informado que "este homem das letras conquistou grande popularidade em textos impregnados de sensualismo exaltado" e que “escreveu mais de uma trintena de volumes (!), por vezes com o pseudónimo Rabelais". O responsável pela elaboração da pequena biografia relembra alguns títulos de romances escritos por Gallis: A amante de Jesus, Lascivas, Sensações fortes, Sensuais, O sensualismo na antiga Grécia, O marido virgem, O algoz, A luxúria judaica, Mártires da virgindade, Devassidão de Pompeia, $O$ abortador, entre outros, ressaltando que todos tinham títulos muito sugestivos. $\mathrm{O}$ redator também relembra que Gallis escreveu dois volumes que serviram de complemento à História de Portugal, com o título Um reinado trágico, datados de 1908 e 1909, mas que, curiosamente, o primeiro volume não trazia o nome do autor.

2 Projeto destinado à memória de escritores e jornalistas, todos já falecidos, que fizeram parte do concelho do Barreiro. Disponível em: http://www.vinculadosaobarreiro.com/01gallis/texto1.html. Acesso em 15 out. 2015. 


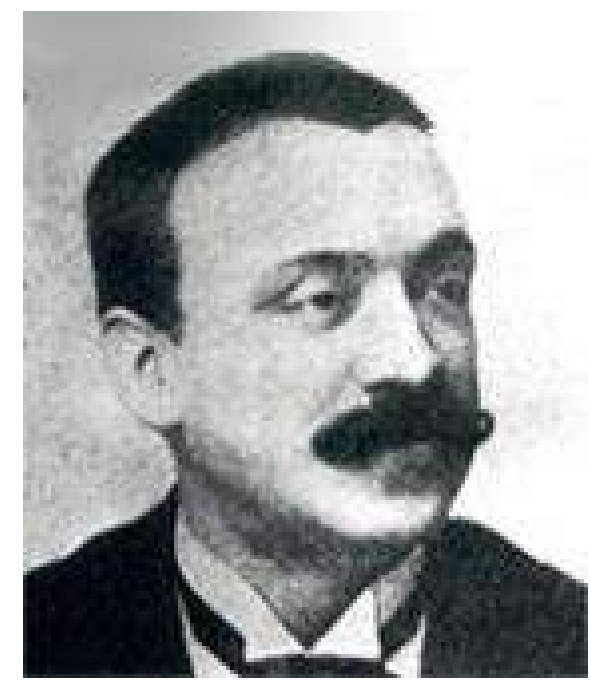

Fig. 1: Joaquim Alfredo Gallis (1859-1910) Fonte: Site Vinculados ao Barreiro.

De acordo com Santana (2004), "Gallis foi um novelista prolífico” cuja produção literária está distribuída "numa escala descendente que abrange desde obras de índole mais ou menos respeitável, até às mais desqualificadas", e foi exatamente sua tendência à literatura de "baixa índole" que fez com que o autor permanecesse "praticamente desconhecido da crítica e ainda hoje é mais fácil encontrá-lo nos alfarrabistas do que nas bibliotecas” (2004, p. 240). Sua impressionante popularidade no final do século XIX, segundo Santana, "não se explica pela qualidade literária - que não tem -, mas decerto pela falta de concorrência, dado que apenas a novela francesa alimentava o mercado da literatura erótica da época" (2004, p. 240). Os dados fornecidos por Antoinio Ventura não são diferentes. O crítico ressalta que "nos finais do século XIX sucederam-se as publicações de cariz licencioso" e que Rabelais, pseudônimo mais famoso de Gallis, foi o mais "prolífero de todos os autores dessa época" (2011, p. 167-8).

Ambas as fontes salientam a importância do ciclo de romances naturalistas "Tuberculose social", composto de doze volumes publicados entre 1901 e 1904: Chibos, Os predestinados, Mulheres perdidas, Os decadentes, Malucos, Os políticos, Sáficas, A taberna, Casas de hóspedes, A sacristia, Mulheres honestas e Os pelintras. Para Maria Helena Santana, essa série "merece poucos comentários", pois "trata-se de uma (mais uma) série romanesca dedicada ao que na altura se designava por chagas sociais - a saber, o adultério, a prostituição, o alcoolismo, enfim, a dissolução dos costumes nas várias classes sociais" (2004, p. 240). Ventura, novamente, diz algo semelhante ao confirmar que "estes ciclos estavam muito em moda" naquela época e que "Gallis assegurava coleções inteiras de pequenos folhetos que eram, certamente, aguardados com curiosidade e expectativa nos locais discretos onde se vendiam" 
(2011, p. 171-2). Essa discrição era necessária, pois alguns desses livros exploravam "de forma bastante libertina o deboche sexual das classes altas, deixando antever, logo pelo título - Sáficas e Chibos -, o verdadeiro atrativo que os motiva" (SANTANA, 2004, p. 241).

Nossa pesquisa pôde contar com valiosas ferramentas de busca online, preenchendo as lacunas biográficas através do cuidado de algumas instituições em digitalizar periódicos antigos, nos quais foram encontrados não apenas textos escritos por Gallis em sua ativa carreira jornalística, como também artigos e anúncios de outros escritores sobre ele. Todo esse material reunido se configura como uma coletânea ainda inédita de dados, que nos proporciona compreender quem era Alfredo Gallis e como ele era apreciado - ou detratado - em seu próprio tempo.

Destacamos a importância da Hemeroteca Municipal de Lisboa, ${ }^{3}$ em que pudemos descobrir a colaboração jornalística do autor em periódicos que não foram citados por nenhuma das fontes biográficas mencionadas: O Branco e Negro: revista semanal illustrada para Portugal e Brasil, no ano de 1899, cuja ficha histórica enfatiza o tom "pedagógico e moralizador" de Gallis em seu engajamento político e social ${ }^{4}$ A illustração portugueza: revista litteraria e artística, em que o autor colaborou entre os anos de 1885 a 1888; Jornal de Domingo, no qual Gallis publicou os contos "Magdalena" (ano II, no 37, 1882), "O tonel do barão Atulfo" (ano II, nos 44 e 45, 1882) e "O ultimo desejo de Clairette" (ano II, no 50, 1883); e no jornal esportivo $O$ Tiro Civil, no qual Gallis mostrou sua diversidade criativa ao escrever uma breve biografia sobre o engenheiro naval Guilherme Arnaud, em 1897.

No Brasil há de se destacar a importância do Real Gabinete Português de Leitura e sua dedicação em manter vivas as relações socioculturais entre Brasil e Portugal. Através do projeto "O Real em Revista", 5 o RGPL também atua na digitalização de um valioso acervo de periódicos brasileiros e portugueses oitocentistas, e, nesse espaço virtual, também pudemos constatar a participação ainda não conhecida de Gallis em outras três revistas: Nova Alvorada: revista mensal litteraria e scientifica, O Antonio Maria e o periódico Pontos Nos II, editado pelo famoso caricaturista Rafael Bordalo Pinheiro (1846-1905). Essas publicações revelam um Gallis bastante versátil, capaz de escrever sobre a sociedade e a literatura produzida em seu tempo.

3 Disponível em: http://hemerotecadigital.cm-lisboa.pt/. Acessso em 20 nov. 2015. 4 Disponível em: http://hemerotecadigital.cm-lisboa.pt/FichasHistoricas/OBrancoeNegro.pdf. Acesso em 20 nov. 2015.

5 Disponível em: http://www.docvirt.com/DocReader.net/DocReader.aspx?bib=RealGabObrasRaras. Acesso em 14 nov. 2015. 
Na coluna "Picarescos da semana", do jornal O Antonio Maria, ao anunciar o lançamento de mais um volume do Almanack das Senhoras, o redator parece surpreso com a colaboração de Gallis. Sendo “o sr. Alfredo Gallis, de pseudonymo Rabelais, que é, essencialmente, distincto literato... só para homens", parecia estranho que pudesse ter algo a dizer às mulheres. ${ }^{6}$ Esse pequeno anúncio revela que Gallis possuía fama duvidosa, imprópria para as digníssimas senhoras burguesas que leriam o almanaque à procura de entretenimento e dicas úteis para o cotidiano. Gallis escrevia "para homens", como se dizia na época, e as mulheres de boa índole deveriam se manter longe.

Por outro lado, pudemos constatar que a opinião pública a respeito de Gallis era ambígua, pois, ao mesmo tempo em que se fazia questão de alertar os leitores de sua fama peculiar de pornógrafo, suas habilidades como polígrafo e escritor também eram consideradas, como uma espécie de atestado de qualidade. É o caso do anúncio do livro de contos Sob magnolias, de Luiz Trigueiros, que foi prefaciado por "uma curta mas valiosa apreciação do distincto escriptor e illustrado critico o sr. Alfredo Gallis". 7

Apesar da nacionalidade portuguesa de Gallis, são as informações contidas em artigos publicados nos jornais brasileiros da virada do século XIX para o XX - disponibilizados pela Hemeroteca Digital Brasileira - que nos permitem ter uma noção mais ampla da grande fama que o autor possuía como escritor pornográfico. Esse fato nos leva a pensar que, talvez, o público português não se interessasse muito pelos romances e contos pornográficos que Gallis escrevia, valorizando mais a sua carreira como sério e respeitado jornalista. No Brasil, entretanto, seu pseudônimo Rabelais era um dos mais conhecidos entre os leitores das "obras imorais" que enchiam as estantes das livrarias populares no Rio de Janeiro e nas capitais das províncias.

Segundo El Far (2004), muitas livrarias possuíam uma categoria especial chamada de "Obras de Rabelais", e isso é apenas um dos indícios da popularidade do escritor no Brasil. Produzidas em formato de brochuras de baixo custo, essas obras eram vendidas a preços populares, mas as grandes tiragens necessárias para suprir a demanda dos ávidos leitores eram suficientes para fazer com que um livreiro lucrasse muito, independentemente do valor cobrado por cada volume.

6 O Antonio Maria, Lisboa, ano. 7, 23 jul. 1891, p. 163. Disponível em: http://hemerotecadigital.cm-lisboa.pt/. Acesso em 26 mar. 2016.

7 Pontos Nos II, Carmo, ano 3, 10 dez. 1887, p. 387. Disponível em: http://hemerotecadigital.cm-lisboa.pt/. Acesso em 26 mar. 2016.

Revista Graphos, vol. 19, n² 2, 2017 | UFPB/PPGL | ISSN 1516-1536 


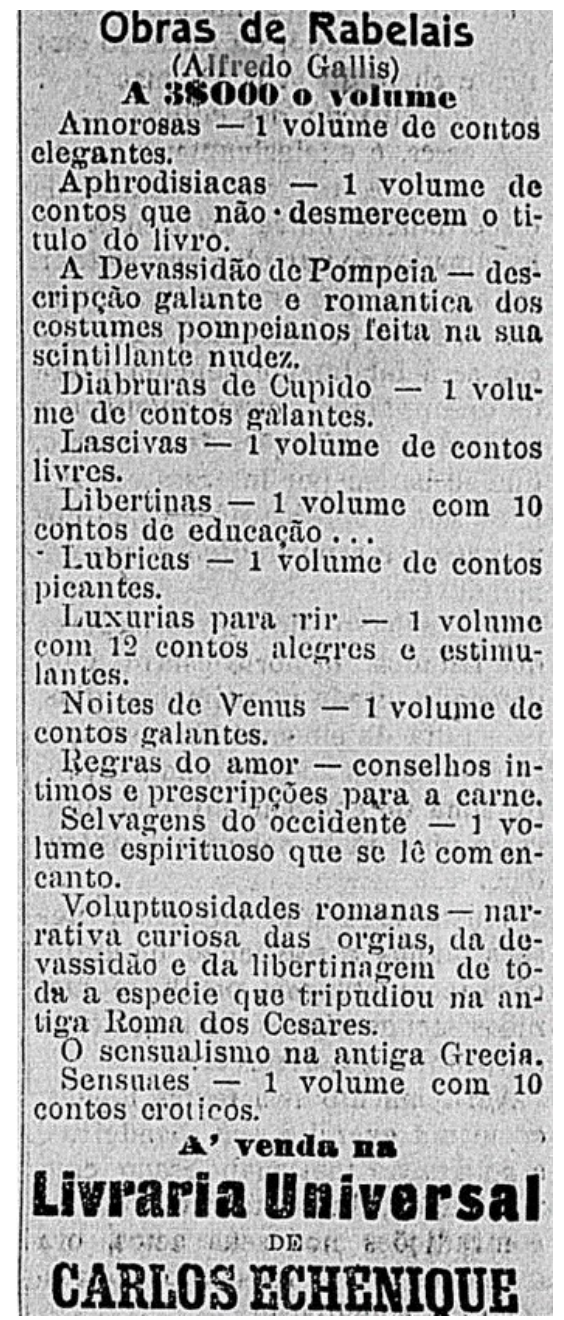

Fig. 2: Obras de Rabelais à venda na Livraria Universal, de Porto Alegre Fonte: A Federação, 20 de maio 1913.

Qualquer associação a esse pseudônimo funcionava como garantia do teor malicioso das obras, algo que Pedro Quaresma, proprietário da Livraria do Povo e um dos mais importantes livreiros brasileiros do final do século, soube aproveitar em suas táticas de propaganda. Ao anunciar o livro Os crimes do amor, Quaresma chama atenção para o fato de essa ser uma "Leitura quente!!!", composta de "mysterios e iniquidades", reforçando que se trata de um livro do "apreciado, procurado e adorado Rabelais", a quem o livreiro também chama de "immortal" (EL FAR, 2004).

A fama - e infâmia - de Rabelais era fruto de um mercado livreiro bastante receptivo para essas “obras destinadas ao público masculino" (EL FAR, 2004, p. 240), que, nas duas últimas décadas do século XIX, viu crescer o interesse por histórias picantes. Era comum nos jornais da época separar os anúncios dos livros pornográficos através de categorias bastante sugestivas, 
tais como "bibliotheca do solteirão", "leitura [só] para homens", "leitura quente", entre outras, sempre deixando claro ao leitor do que se tratava daquele determinado livro. Esses nomes não passavam de um eufemismo para designar a literatura licenciosa.

Talvez numa tentativa de negar a importância da literatura popular e pornográfica para a história da leitura, convenciou-se que o brasileiro da época não lia (MENDES, 2014). Uma das causas para isso é que, na medida em que esses livros populares vendiam mais do que aqueles escritos por autores aclamados, as grandes tiragens e reedições dos livros pornográficos eram não só uma afronta aos bons costumes, como também uma ofensa aos escritores dedicados à propagação dos ideais burgueses. Em 1903, num trecho da crítica ao obscuro romance Guilota, de certo Alfredo Azamor, o articulista desabafa sobre o pouco interesse do público pelas obras de Gonzaga Duque (1863-1911), B. Lopes (1859-1916) e Domingos Olímpio (1851-1906), em contraste com a popularidade dos "manuais de estroinices nojentas" assinados por escritores como Alfredo Gallis. ${ }^{8}$

Não só os anúncios dos livros de Gallis atestam a sua popularidade no Brasil daquele tempo. Diversas notas a respeito de sua vida pública e pessoal, como seus discursos e a ocasião de seu casamento, também podiam ser vistas nos jornais. A morte do escritor foi noticiada no Brasil, e o teor dessas notícias revela que, mesmo com tanta popularidade, as opiniões a seu respeito não eram sempre positivas. O jornal $A$ Federação, de Porto Alegre, informou apenas que "falleceu em Lisboa o conhecido jornalista Alfredo Gallis". ${ }^{9}$ O Correio Paulistano foi mais detalhista e crítico, citando que era lastimável que um escritor do gabarito de Gallis pecasse por um "excesso de 'crueza' naturalista". ${ }^{10}$

Outra prova de popularidade é a menção do nome do autor numa crônica de João do Rio (1881-1921) sobre a reabertura da Biblioteca Nacional, intitulada "Os leitores da Biblioteca", publicada na Gazeta de Notícias, no Rio de Janeiro, em 1905. Isso é revelador, pois, em meio à agitação causada pela voga de obras escandalosas, o famoso cronista desprezava "tais 'romances mal escritos', temendo sua influência perniciosa sobre os leitores propensos a uma "vida de degeneração"”. Esse posicionamento, entretanto, "fornece, para quem estuda aquele período, uma preciosa descrição sobre a disseminação da leitura entre as camadas marginalizadas e de baixa renda" (EL FAR, 2004, p. 72). Contudo, é o próprio João do Rio

8 O Fluminense, Niterói, n. 5354, 27 out. 1903, p. 2. Disponível em: http://bndigital.bn.gov.br/hemeroteca-digital/. Acesso em 20 mar. 2016.

9 A Federação, Porto Alegre, n. 273, 26 nov. 1910, p. 1. Disponível em: http://bndigital.bn.gov.br/hemerotecadigital/. Acesso em 30 nov. 2015.

10 Correio Paulistano, São Paulo, n. 17.022, 21 dez. 1910, p. 6. Disponível em: http://bndigital.bn.gov.br/hemeroteca-digital/. Acesso em 28 nov. 2015.

Revista Graphos, vol. 19, n² 2, 2017 | UFPB/PPGL | ISSN 1516-1536 
quem confirma que esses livros não eram consumidos apenas entre a parcela inferior da sociedade; ao traçar o perfil dos vários tipos de frequentadores da "Bibliotheca", ele descreve o comportamento dos leitores, que iam desde o jovem estudante em busca de livros didáticos, até "os immoraes que escrevinham, com sorrisinhos equivocos, o pedido de Alfredo Gallis". ${ }^{11}$

Por fim, outro registro pôde ser encontrado num dos livros mais populares do fim de século, O aborto (1893), de Alberto Figueiredo Pimentel (1869-1914). Romance naturalista que flerta com o gênero pornográfico, $O$ aborto narra o relacionamento fora do casamento entre primos, o estudante Mário e a espevitada Maricota, que, contrariando a rígida moral da sociedade oitocentista, experimentam as descobertas do desejo sexual. Em um baú secreto, Mário guardava romances naturalistas como O crime do padre Amaro (1875), de Eça de Queirós (1845-1900), Nana (1880), de Émile Zola (1840-1902), e o volume de contos Volúpias (1886), de Rabelais (Alfredo Gallis), entre outros. Ao encontrar a pequena biblioteca proibida às mulheres, Maricota aprende, às escondidas da mãe, "coisas completamente ignoradas, e reparando em vários episódios que não compreendia bem, mas onde pressentia grandes imoralidades" (PIMENTEL, 2015, p. 72).

A aparição de Rabelais no romance de Figueiredo Pimentel nos fornece um documento histórico irrefutável, embora literário, ampliando o nosso entendimento a respeito da fama espetacular que Alfredo Gallis possuía em vida. A aparição de Volúpias, livro de contos publicado em São Paulo, pela Livraria Teixeira, em 1886 - a obra licenciosa mais popular de Gallis -, num romance também popular e licencioso, sugere que a ficção naturalista, mesmo a mais celebrada pela historiografia, era lida preferencialmente como forma de entretenimento pornográfico (MENDES, 2016), num universo de leitura que se dava "somente pelo lado da bandalheira" (PIMENTEL, 2015, p. 72).

\section{Naturalismo e pornografia}

A associação entre naturalismo e pornografia remete às origens da literatura pornográfica. Desde a origem, a pornografia manteve laços estreitos com o pensamento científico. Margaret Jacob (1999) chama a atenção para a "transformação filosófica" que ocorreu na Europa entre os séculos XVII e XVIII. A autora se refere à mecanização da natureza: "os corpos foram atomizados, despidos de sua aparência e qualidade, sendo reconhecíveis apenas pelo tamanho,

11 Gazeta de Notícias, Rio de Janeiro, n. 37, 6 fev. 1905, p. 2. Disponível em: http://bndigital.bn.gov.br/hemeroteca-digital/. Acesso em 15 jun. 2015.

Revista Graphos, vol. 19, n² 2, 2017 | UFPB/PPGL | ISSN 1516-1536 
forma, movimento e peso" (1999, p. 169). Em termos filosóficos, esse é um dado importante, uma vez que representa a passagem do paradigma teocêntrico para a humanização e racionalização do homem. Esse novo modelo social reconhece o homem como indivíduo livre das convenções tradicionais da Igreja e do ideal da instituição familiar; não mais um ser espiritual, mas pura matéria em movimento, entregue aos domínios da natureza. Isto indica que só através do posicionamento científico se pôde conceber um gênero pornográfico, uma vez que o discurso da ciência fornecia as metáforas e conceitos necessários.

Nesse sentido, as teses científico-literárias do naturalismo ofereciam um terreno fértil para a retomada da perspectiva materialista e mecanicista do ato sexual. Analisadas sob esse ponto de vista, as obras naturalistas revelavam que o argumento das chamadas "patologia sociais" não existia apenas por mera influência das novas descobertas científicas, mas também para explorar e comprovar a crença de que a sociedade era impotente ante a natureza (DUARTE, 2015). Ao tomar o corpo e a carnalidade como um de seus principais "objetos de estudo", o naturalismo aliou-se à pornografia no que parecia uma causa comum: denunciar a hipocrisia da sociedade através de um novo discurso sobre o sexo.

De acordo com crítico de arte Alexandrian, em seu estudo História da literatura erótica, ao "mostrar personagens 'dominados por seus nervos e seu sangue, desprovidos de livre arbítrio", "a escola naturalista teve uma reputação de imoralidade cujo custo Zola começou a pagar em 1868, com Thérèse Raquin” (1993, p. 273). A ficção naturalista era composta por obras que buscavam revelar "os males" da sociedade, especialmente no domínio da sexualidade e da vida íntima. Como resposta, esses livros foram considerados imorais pela rígida moral burguesa da época, que classificava de pornográfica toda a literatura que, de alguma forma, ofendesse os bons costumes ao excitar o apetite sexual do leitor, independentemente de sua intenção científica.

Assim, entendemos por que romances naturalistas, como A carne (1888), de Júlio Ribeiro (1845-1890), ou O homem (1887), de Aluísio Azevedo (1857-1913) - que também eram guardados no baú de livros licenciosos do estudante Mário, em $O$ aborto -, eram acusados de pornográficos, eróticos ou apenas imorais. Isso ocorria embora raramente tratassem do sexo de maneira que hoje consideraríamos explícita, uma vez que a temática sexual servia apenas de pano de fundo para a trama, e não como elemento principal. Gallis, cuja formação era naturalista, também se apropriou da pornografia em seus romances. Em Mártires da virgindade (c.1900), o autor diz que seu objetivo era "apresentar, ao vivo, uma das mais monstruosas violências do nosso tempo" (GALLIS, s. d., p. 17): o celibato forçado da mulher sem marido. 
Não é nossa intenção ponderar se o autor defendia ou não a autonomia sexual feminina, mas a descrição da protagonista Maria Manuela reproduz o estereótipo da mulher hipersexualizada (DUARTE, 2015). Isso era mais do que suficiente para que esse tipo de ficção naturalista fosse rotineiramente confundida com literatura pornográfica (MENDES, 2014).

Contudo, Gallis também escrevia livros que, mesmo para os padrões atuais, podem ser considerados pornográficos, uma vez que traziam o sexo como tema principal. Principalmente nas obras assinadas pelo pseudônimo Rabelais. Tomando carona no sentido de "carnalidade triunfante" (BAKHTIN, 1987) associado ao escritor renascentista homônimo, Gallis revisitava as marcas da tradição licenciosa que se estendeu dos séculos XVII aos dias de hoje. Em Volúpias, Gallis explora temas caros a essa tradição, como o voyeurismo/exibicionismo, o falocentrismo (ode ao pênis), a abolição das hierarquias pelo sexo, a prostituta como personagem paradigmática, a fantasia da sexualidade desregrada dos antigos, assim como o caráter "pedagógico" dos manuais que ensinavam o que fazer durante o ato sexual.

O "perigo" dessa e outras obras estava no fato de apresentarem casos de relações sexuais escandalosas para a época, entre as quais o adultério, o incesto, o amor entre pessoas do mesmo sexo, a prostituição e outros tipos de comportamentos tidos por imorais, posto que eram estabelecidos além do sagrado ambiente do matrimônio, e sua prática se configurava como uma ofensa aos bons costumes. Além disso, romances como A amante de Jesus e As doze mulheres de Adão atacavam diretamente a moral religiosa, a partir do anticlericalismo que foi bastante popular entre os escritores licenciosos, a exemplo de Os serões do convento (s.d.), uma das obras pornográficas mais conhecidas na segunda metade do século XIX, publicada por um autor desconhecido sob o pseudônimo de M. L. (MENDES, 2016).

No Brasil do final do século, não havia legislação que proibisse a produção e venda de obras licenciosas, ao contrário do que aconteceu na França com Madame Bovary e As flores do mal. Ambas publicadas em 1857, são exemplos conhecidos de obras que foram não apenas rotuladas, mas também levadas aos tribunais e acusadas de imorais. No país de Gustave Flaubert (1821-1880) e Charles Baudelaire (1821-1867), a proibição vinha de autoridades religiosas e políticas, que se sentiam atacadas por essas narrativas. No Brasil, por outro lado, o caráter da proibição não era jurídico, mas moral e religioso (EL FAR, 2004). O Código Penal de 1890 não proibia a publicação e circulação de impressos pornográficos (MENDES, 2016). A moralidade pública era o que enquadrava a literatura em uma posição aceitável ou condenável, e esse julgo de valor afetava os escritores que ousassem nessa vertente literária. A censura, ao contrário do que poderiam esperar os poderosos que procuravam regulamentar a pornografia, acabava por 
intensificar a popularidade das obras, pois, quanto mais denunciadas, mais eram cobiçadas e vendidas.

\section{Considerações finais}

De posse dessas informações, somos levados a reconhecer que é necessário assumir o distanciamento necessário à toda pesquisa científica, a fim de compreender como os leitores do período recebiam esses livros. O pesquisador deve tentar captar o imaginário da época. Os exemplos de obras licenciosas apresentadas nesse trabalho revelam que não era preciso colocar o ato sexual em destaque para que a leituta pornográfica se concretizasse, como se espera nos dias de hoje. Numa sociedade patriarcal e repressora, em que o sexo era tabu, qualquer representação do corpo e do desejo sexual era capaz de disparar a imaginação pornográfica e devia ser interditada.

Em relação a Alfredo Gallis, não nos cabe especular se o escritor sabia que preço estava pagando por se "manchar" com a moda pornográfica de seus contemporâneos. Seu nome está ausente dos principais manuais de literatura, salvo apenas para colocá-lo na categoria de "outros prosadores", afastando-o dos escritores naturalistas consagrados pela historiografia tradicional (MOISÉS, 1994). Gallis é um autor vitimado pela ambiguidade de seu reconhecimento público diante do rígido convencionalismo que determina a historiografia literária. Não importa que ele tenha sido um jornalista conhecido ou que tenha atuado na política. Importa menos ainda que tenha vendido tantos volumes, principalmente num período em que a literatura francesa e os romances psicológicos dominavam a cena literária ocidental.

As informações obtidas ao longo da pesquisa, por vezes, fizeram-nos questionar: havia mais de um Alfredo Gallis? Mas descobrimos se tratar de apenas um autor, esse que talvez seja um dos mais complexos escritores da língua portuguesa. Isso posto, podemos reconhecer, pelo menos, três personae: o Gallis dos textos jornalísticos respeitados por seus contemporâneos; o Alfredo Gallis que, embora não seja lembrado pelos manuais, também fez parte do grupo dos escritores naturalistas, dedicando-se aos chamados romances de "patologia social", nos quais revelava, através da descrição das chamadas "perversões sexuais", a hipocrisia da sociedade burguesa; e por último, talvez a mais importante para a história da leitura no Brasil, a persona, às vezes chamada por outros nomes, mas quase sempre lembrada como o "imortal Rabelais", que escreveu inúmeros contos e romances com apelo pornográfico acentuado, que chamava a atenção do leitor antes mesmo que o livro fosse aberto, porque seus títulos não apontavam para 
nada além da sensualidade. Assim, a verdade sobre Gallis, se um único trabalho for capaz de descobrir, é que ele foi um escritor no sentido mais completo da palavra.

Seu caráter popular e arrojado o fez se tornar um dos autores mais conhecidos nas últimas décadas do Oitocentos. As "obras de Rabelais" possuíam anúncios exclusivos nos principais jornais brasileiros no Rio de Janeiro, Recife, Porto Alegre e São Paulo. Mas a história da literatura é a história dos escritores vitoriosos, dos homens eleitos, dos grandes imortalizados pelas grandes academias. Ela ignora os que não têm nome, os "menores" e suas minorias, aqueles que, enclausurados pela raça, pelo gênero, pelo status social ou pela escrita licenciosa, se perdem nas discriminadoras páginas do tempo. No caso singular de Alfredo Gallis, percebemos a força do decoro social da época, pois, nesse ponto, é praticamente impossível negar que o esquecimento do autor se deveu à percepção do caráter "imoral" de grande parte de suas obras, e não pelo fato de ter fracassado como escritor na sociedade de seu tempo.

\section{Referências}

ALEXANDRIAN. História da literatura erótica. Rio de Janeiro: Rocco, 1993.

BAKHTIN, Mikhail. A cultura popular na Idade Média e no Renascimento: o contexto de François Rabelais. São Paulo: HUCITEC; Brasília: Editora da Universidade de Brasília, 1987.

BOURDIEU, Pierre. Por uma ciência das obras. In: . Razões práticas: sobre a teoria da ação. Campinas: Papirus, 1996. p. 53-89.

DUARTE, Aline Moreira. Naturalismo, histeria e pornografia em Mártires da virgindade, de Alfredo Gallis. Soletras, n. 30, p. 139-157, jul/dez. 2015.

EL FAR, Alessandra. Páginas de sensação: literatura popular e pornográfica no Rio de Janeiro (1870-1924). São Paulo: Cia. das Letras, 2004.

MENDES, Leonardo. Biblioteca picante: o naturalismo como produto erótico. In: HELENA, Lucia; OLIVEIRA, Paulo César de (Orgs.). Literatura, arte e mercado: XI Seminário NaçãoInvenção. Niterói, RJ: Instituto de Letras da Universidade Federal Fluminense, 2014, p. 8395.

Livros para Homens: sucessos pornográficos no Brasil no final do século XIX. Cadernos do IL, Porto Alegre, n. ${ }^{\circ}$ 53, janeiro de 2017. p. 173-191.

MOISÉS, Massaud. A literatura portuguesa em perspectiva, v. 3. São Paulo: Atlas, 1994.

PIMENTEL, Alberto Figueiredo. O aborto. Organização de Leonardo Mendes e Pedro Paulo

Garcia Ferreira Catharina. 1. ed. Rio de Janeiro: 7Letras, 2015. 
SANTANA, Maria Helena. Pornografia no fim do século: os romances de Alfredo Gallis.

Portuguese Literary and Cultural Studies, n. 12, 2004, p. 235-248.

VENTURA, Antônio. Rabelais, isto é, Alfredo Gallis, o pornógrafo. In: GALLIS, Alfredo. Aventuras galantes. Lisboa: Edições Tinta da China, 2011, p. 167-174.

RECEBIDO EM 20-05-2017

APROVADO EM 30-05-2017 